\title{
NEW TEST OF THE VELOCITY OF LIGHT POSTULATE
}

\author{
FRED B. ROTZ \\ Institute of Science and Technology, University of Michigan \\ Ann Arbor, Michigan
}

Received 5 November 1963

A good deal of theoretical and experimental activity 1) related to Einstein's "velocity of light postulate" has arisen from recent papers by Kantor 2) and Fox 3 ). These authors have raised a number of questions concerning Einstein's postulate that "light is always propogated in empty space with a definite velocity which is independent of the state of motion of the emitting body" 4). Fox, in his paper published about one month before Kantor's paper, casts doubt on the interpretation of a number of past experiments which have usually been taken as verifying the correctness of the postulate. Kantor reports an interferometric experiment performed in air and indicating by its qualitative results an apparent and significant contradiction with Einstein's velocity of light postulate. Many of Fox's questions rely on the so-called extinction theorem of Ewald and Oseen 5). More recently, Beckmann 6) has taken Kantor's experiment as disproving this theorem, while White and Alpher 7) suggest that in view of the extinction theorem, "Kantor must seek an explanation elsewhere for such effects as he observes" in his experiment, in particular, in terms of the interpretation of his results as related to the velocity of light postulate.

In view of the considerable interest and work created by the apparent discrepancy of Kantor's observations related to the velocity of light postulate, a need has arisen for not only repeating Kantor's experiment, as he himself suggested, but also for performing a version of the experiment which, while similar enough to Kantor's to allow comparison of results, also avoids many of the objections to this and past experiments in this area. In particular, of course, our experiment was performed in vacuo.

It is the purpose of this letter to give a first account of the results and a brief account of the experimental arrangement, inasmuch as our results are at variance with Kantor's observations. Indeed, we find no disagreement with the velocity of light postulate to the order of $o$ being less than 0.1 in vacuo. A brief description of the experiment and the significance of $o$ follows.

Our experiment is capable of measuring the dif- ference between the velocity in vacuo of three beams of light, where one of these beams has passed through a piece of glass, which may be moved at a constant speed or kept stationary as desired. The velocity difference is determined by a measurement of the phase shift between the beams. If it is assumed that the glass serves as a moving source whose velocity affects the velocity of light, then it would be expected that the phase shift measured when the glass is moving will differ from the shift associated with the stationary glass. The important point here is that we are measuring velocity differences over a free vacuum path between optical elements and thus are avoiding one of the major objections to previous tests of the postulate, namely that stationary optical elements in the system obliterate velocity differences 3 ).

The apparatus employed is a three beam interferometer of the type first described by Zernike in $19508)$. The central beam passes through a piece of glass. The apparatus was arranged by mounting the three slits forming the interferometer beams on the periphery of a wheel and cementing a piece of glass over the central slit. The wheel, which can be made to rotate at uniform velocity, also carried a self-shuttering arrangement which allowed illumination of the slits only when the glass was moving parallel to the beams, or was at rest in the proper position. The entire apparatus was enclosed in a vacuum chamber. The light beams leaving the glass and slits traveled a known distance in vacuo before reaching a flat $\left(\frac{1}{4} \lambda\right)$ glass window in the wall of the chamber. The diffraction pattern of the slits was formed by an objective lens and observed through a microscope mounted on a graduated optical bench in the usual manner. The light source was a $\mathrm{CW}$ gas laser providing monochromatic light at $6328 \AA$ and operating in a single mode.

The three beam interferometer allows precise determination of a phase shift between its central and side beams, and thus precise measurement of phase shift caused by a sample placed in the central beam. Precision as good as $\frac{1}{200} \lambda$ is possible with this three beam technique using merely visual 
observation. If, as assumed, the motion of the glass affects the velocity of light, this should produce a shift in the location of the planes in which the central beam is $\frac{1}{4} \lambda$ out of phase with the side beams (hereafter called the $\frac{1}{4} \lambda$ planes). The relation of such a phase shift to the location of a particular $\frac{1}{4} \lambda$ plane is given by the expression

$$
\Delta \varphi=\frac{d^{2}}{2 \lambda}\left(\frac{1}{r_{\text {stationary }}}-\frac{1}{r_{\text {moving }}}\right),
$$

where $\Delta \varphi$ is the phase shift expressed in wavelengths, $d$ is the spacing between the central and side slits, $\lambda$ is the wavelength, and $r$ is the distance from the objective lens to the $\frac{1}{4} \lambda$ plane. These $\frac{1}{4} \lambda$ planes can be very accurately located through observation of the diffraction pattern.

It can be shown * that, if it is assumed that light propagates in the glass with a velocity $c+\sigma v$ and with a velocity $c+\rho v$ upon leaving the glass, then the phase shift between the central and side beams due to the motion of the glass is given in terms of wavelengths of light by the expression

$$
\Delta \varphi=\frac{\beta}{\lambda}\left[\rho(l-L)+l\left\{n^{2}(1-\sigma)-n\right\}\right],
$$

where $\beta=v / c$ ( $v=$ velocity of glass), $n$ is the index of refraction of the glass, $l$ is the thickness of the glass, $L$ is the distance from where light enters the glass on the central slit to where it enters the next optical element, $\sigma$ is the velocity addition coefficient for the glass (according to the special theory of relativity this should be $1-n^{-2}$ ), and $o$ is the velocity addition coefficient due to source motion (from relativity this should be zero in vacuum).

In our experiment, these parameters have the following values; $\varepsilon=2 \times 10^{-7}, n=1.5, l=1.5 \mathrm{~mm}$, $L=0.57 \mathrm{~m}$ and $1.48 \mathrm{~m}, \mathrm{~d}=5.5 \mathrm{~mm}$. The slits were mounted at a radius of $12 \frac{1}{2}$ inches and the wheel revolved at $29.7 \pm 0.1 \mathrm{rps}$. The focal length of the objective was 42 in. Phase shift due to tilting of the glass was kept to less than $0.2 \lambda$ by the limiting the aperture of the shutter to $2 \mathrm{~mm}$. The width of the central slit was $0.5 \mathrm{~mm}$ and the side slits were half as wide. Vacuum chamber pressure was maintained between $6 \times 10^{-4}$ and $1.2 \times 10^{-3}$ torr. The diffraction pattern was sharp and clear both when the wheel was stationary and when it was running. There were no vibration problems.

Introducing the values of the appropriate parameters in eq. (2) gives a $\Delta \varphi$ of $\frac{1}{6} \rho \lambda$ and $\frac{1}{2} \rho \lambda$ respectively for the two values of $L$. Such a shift should be readily detectable with our apparatus if $\rho$ is on the order of 0.1 to 1.0 . The phase shift between stationary and

\footnotetext{
* A more extensive development of the results described here will be presented in a more comprehensive paper in the near future. See also Kantor's paper for a similar expression as (2).
}

moving glass was measured at three adjacent $\frac{1}{4} \lambda$ planes (A, B and C). Our results, given in table 1 , show that no significant shift occurred.

The variance, $\sigma$ of the measurements is also given. Visual observation of a particular $\frac{1}{4} \lambda$ plane while the wheel was brought from rest to full speed revealed no significant change in the diffraction pattern.

Table 1

Experimental Results

\begin{tabular}{|c|c|c|c|c|c|c|}
\hline $\begin{array}{l}\text { Run } \\
\text { no. }\end{array}$ & $\begin{array}{l}\text { No. of } \\
\text { shift } \\
\text { determi- } \\
\text { nations }\end{array}$ & L & A & B & C & \multicolumn{1}{l|}{$\begin{array}{l}\text { Aver- } \\
\text { age }\end{array}$} \\
\hline 1 & 24 & $0.57 \mathrm{~m}$ & $\Delta \varphi=+0.01 \lambda$ & $+0.01 \lambda$ & $+0.01 \lambda$ & $+0.01 \lambda$ \\
& & & $\sigma=0.02 \lambda$ & $0.02 \lambda$ & $0.02 \lambda$ & $0.03 \lambda$ \\
2 & 57 & $1.48 \mathrm{~m}$ & $\Delta \varphi=-0.02 \lambda$ & $-0.02 \lambda$ & $-0.02 \lambda$ & $-0.02 \lambda$ \\
3 & 18 & \multirow{2}{*}{$0.57 \mathrm{~m}$} & $\begin{aligned} \Delta \varphi=0.03 \lambda \\
0.03 \lambda\end{aligned}$ & $0.03 \lambda$ & $0.05 \lambda$ \\
& & & $\sigma=0.02 \lambda$ & $0.00 \lambda$ & $0.00 \lambda$ & $0.00 \lambda$ \\
& & & & $0.03 \lambda$ & $0.01 \lambda$ & $0.04 \lambda$ \\
\hline
\end{tabular}

It is clear that more work is required in order to account for any possible cancellations of first order effects by any effect of phase retardation (or lead) by the passage of light through the "open" slits, and any other possible self-cancelling effects. This part of the work is under way and will be reported on more extensively in a complete publication along with side-experiments used to clarify any possible spurious effects. It was felt that the present results were obtained with a sufficiently good apparatus and were comparable enough to the previously mentioned work, so as to deserve publication in the form of this letter, at this time.

It is a pleasure to acknowledge the interesting and stimulating discussions with Professor George W. Stroke, as well as the encouragement and facilities offered by Dr. W. M. Brown and the Radar Laboratory of the Institute of Science and Technology of the University of Michigan.

\section{References}

1) D. Sadeh, Phys. Rev. Letters 10 (1963) 271.

A. Bierman, C. H. von Kenschitski and D. Pandres, J. Opt. Soc. Am. 53 (1963) 1008.

T.Alvager, A. Nilsson and J.Kjellman, Nature 197 (1963) 1191.

J .F. James and R.S.Sternberg, Nature 197 (1963) 1192 .

P.Burcev, Physics Letters 5 (1963) 44.

2) W.Kantor, J.Opt. Soc. Am. 52 (1962) 978 .

3) J.G. Fox, Am. J.Phys. 30 (1962) 297.

4) A.Einstein et al., The principle of relativity (Dover, 1923). 
5) M. Born and E.Wolf, Principles of optics (Pergamon Press, New York, 1959) p. 70.

6) P. Beckmann, Inst. of Radio Eng. and Elec., Checz. Acad. of Sci., Nos.28 and 30, May 1963.
7) D.R. White and R.A.Alpher, J.Opt. Soc. Am. 53 (1963) 760 .

8) F. Zernike, J. Opt. Soc. Am. 40 (1950) 326. C. Renet and J.Vienot, Revue d'optique 32 (1953) 27.

\title{
PIEGES A PLASMA SANS FUITES
}

\author{
T. CONSOLI \\ Service d'Ionique Générale, Centre d'Etudes Nucléaires de Saclay, \\ Services de Physique Appliquée
}

Reçu le 7 Novembre 1963

On donne le principe de deux structures idéales permettant theoriquement $l^{\prime}$ injection et l'accumulation de charges dans un piège sans fuite. Les cavités qui sont utilisées dans ces structures fonctionnent en "accélérateur et bouchon dynamique" *.

Deux problèmes fondamentaux dans le confinement d'un plasma par un champ magnétique statique sont: 1) les pertes par les miroirs magnétiques, 2) le retour du jet des particules ionisées sur l' injecteur.

L'utilisation d'une structure à gradients de champs électromagnétique et magnétique statique peut résoudre, semblerait-il, ces deux difficultés jusqu'ici non surmontées.

Dans des références antérieures 1-3), le principe et la théorie de ces structures ont éte données. On sait qu'en mettant à profit I'inversion des forces s'exerçant sur des charges placées dans des gradients de champ magnétique statique et haute fréquence, à la résonance entre la fréquence cyclotron et celle du champ, on peut obtenir des forces unidirectionnelles. Ces forces peuvent à volonté s'exercer sur l'un ou l'autre type de particule (ions si $\omega_{\mathrm{HF}}=\omega_{\mathrm{ci}}$ ou électrons si $\omega_{\mathrm{HF}}=\omega_{\text {ce }}$ ) d'un plasma ou d'un faisceau d'ions ou d'électrons. Si nous disposons une telle structure à force unidirectionnelle sur un col d'une bouteille magnétique, la structure a une double fonction: toute particule qui la traverse dans le sens injection voit son énergie augmenter et toute particule qui y retourne est réfléchie ${ }^{4)}$. La structure se comporte à la fois comme un injecteur et comme un "bouchon dynamique" qui réfléchit les particules sans pertes d'énergie **.

\footnotetext{
* D'autres auteurs dont Glagolev et al. en Russie, Braams en Hollande, Johnson (RCA - USA) ont propose des bouchons statiques $\mathrm{HF}$, utilisation différente par leur principe et efficacité des dispositifs proposés.
}

On peut donc concevoir l'une des deux dispositions représentées sur les figures 2 et 3.

La figure 2 est une bouteille classique à deux miroirs, pourvue de deux injecteurs à bouchons. On utilise le sens favorable du gradient du champ magnétique statique comme une partie intégrante de la structure de l'injecteur, soit pour ioniser et accélérer le gaz neutre, soit pour accélérer un jet de plasma ou de particules monocinétiques (électrons ou ions), venant de l'extérieur. Les deux injecteurs font aussi fonction de bouchons dynamiques et $s^{\prime}$ opposent à la sortie des particules qui restent piégées. La capture est totale aux pertes par diffusion et instabilités près.

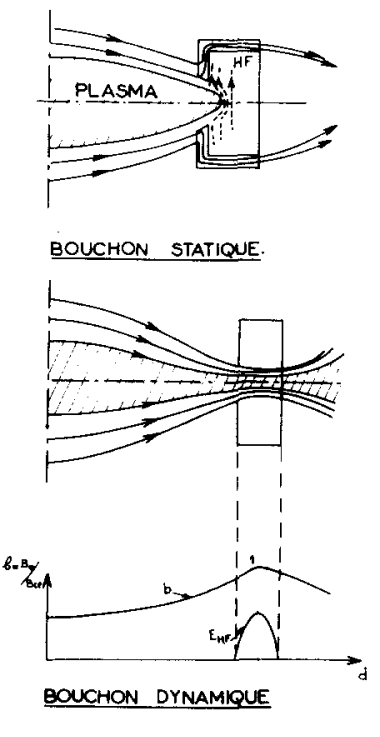

Fig. 1.

** Ce principe de fonctionnement est tres different de celui des "bouchons statiques" proposé précedemment (voir ref. ${ }^{5)}$ ). 